NBER WORKING PAPER SERIES

\title{
THE EFFECTS OF ALCOHOL REGULATION \\ ON PHYSICAL CHILD ABUSE
}

Sara Markowitz

Michael Grossman

Working Paper 6629

http://www.nber.org/papers/w6629

\author{
NATIONAL BUREAU OF ECONOMIC RESEARCH \\ 1050 Massachusetts Avenue \\ Cambridge, MA 02138 \\ July 1998
}

Any opinions expressed are those of the author and not those of the National Bureau of Economic Research.

(C) 1998 by Sara Markowitz and Michael Grosman. All rights reserved. Short sections of text, not to exceed two paragraphs, may be quoted without explicit permission provided that full credit, including $(\mathbb{C}$ notice, is given to the source. 
The Effects of Alcohol Regulation on

Physical Child Abuse

Sara Markowitz and Michael Grossman

NBER Working Paper No. 6629

July 1998

JEL No. I10, J13

\begin{abstract}
The purpose of this paper is to examine the effects of alcohol regulation on physical child
\end{abstract} abuse. Given the established relationship between alcohol consumption and violence, the principal hypothesis to be tested is that an increase in the price of alcohol will lead to a reduction in the incidence of violence. We also examine the effects of measures of the ease of obtaining alcohol, illegal drug prices, and the socio-demographic characteristics of the parent on the incidence of child abuse. Data on violence come from the 1976 and 1985 Physical Violence in American Families surveys. We estimate a reduced form model where violence is affected by the state excise tax rate on beer and other regulatory variables, and a structural model where violence is determined partly by consumption. Both equations are estimated separately for mothers and fathers. Results indicate that increases in the beer tax may decrease the incidence of violence committed by females but not by males. This is consistent with our second finding that violence by females increases with alcohol consumption while violence by males is not sensitive to changes in consumption.

Sara Markowitz

New Jersey Institute of Technology

University Heights

Newark, NJ 07102

and NBER

smarkowi@email.gc.cuny.edu
Michael Grossman

City University of New York Graduate School

33 West 42nd Street

New York, NY 10036

and NBER

mgrossma@email.gc.cuny.edu 


\section{INTRODUCTION}

Child abuse has become a national epidemic. The statistics are grim: more than one million children each year are confirmed as victims of child abuse and neglect by child protective service agencies, and every day at least three children die as a result of abuse and neglect. Many studies have shown that alcohol plays a significant role in incidents of domestic violence. For example, it is estimated that about forty percent of all cases of child maltreatment (including physical abuse, sexual abuse and neglect) involve alcohol (Children of Alcoholics Foundation, 1996). In addition to being subjected to violence, children whose parents have drug and alcohol problems suffer more physical and mental health problems than children in the general population, they have more injuries and poisonings, and more behavioral problems.

This paper studies the link between alcohol use and physical violence aimed at children, with the main purpose of examining the role that changes in alcohol regulatory variables may play in reducing the incidence of physical child abuse. More specifically, the principal hypothesis to be tested is that an increase in alcoholic beverage prices will lead to a reduction in the incidence of violence. We also examine the effects of measures of the prevalence of and ease of obtaining alcohol, illegal drug prices, and the socio-demographic characteristics of the parent on physical child abuse.

\section{THE LINKS BETWEEN ALCOHOL, DRUGS, AND VIOLENCE}

The link between alcohol and violence has been the focus of many biological, psychological, sociological, and epidemiological studies. While each discipline seeks to answer its own questions about the association, for the purpose of this paper one can draw a few main conclusions from the existing literature. First, there is a general agreement that a strong link exists between alcohol consumption and violence. In a variety of settings, alcohol is found to have been used prior to 
assault. There is an overwhelming amount of evidence showing that the use of alcohol is prevalent in many cases of criminal assaults and rapes (see Collins, 1981 for an overview). For example, the Bureau of Justice Statistics (1988) reports that about 60 percent of all persons convicted of assault had been drinking just prior to the crime. By contrast, about 40 percent of burglars and 30 percent of drug offenders used alcohol just prior to the crime for which they had committed. In the context of child abuse, Gil (1973) found that 13 percent of child abuse cases involved a perpetrator who was intoxicated at the time of the attack. ${ }^{1}$ Many other studies link alcoholism to child abuse and neglect. Behling (1979) found that in 69 percent of cases of child abuse at least one parent was an alcoholic. Famularo et al. (1986) found that of parents who had lost custody of their children because of abuse and neglect, 38 percent were alcoholics.

Given the general association between alcohol use and violence, an important question for policy purposes is how alcohol use may promote violent behavior. While this paper makes no attempt to explain the causes of the link, a few theories which are relevant to this paper are discussed. To begin, there is no general agreement in the existing literature on the nature of this observed association. Theories range from simple pharmacological effects to the complex interaction of endocrinological, neurobiologic, environmental, social and cultural determinants. (See National Research Council, 1993 chapter 4, and Goldstein, 1985 for further information.) For example, there may exist a psychopharmacological relationship in which alcohol can alter behavior by increasing excitability and/or boosting courage. (See Pernanen, 1981 and Fagan, 1993 for a complete discussion.) Under this theory, people may be more likely to commit a violent act when under the influence of alcohol than they would otherwise. A second theory asserts that people use alcohol as an excuse for aberrant behavior. Our society teaches people that alcohol use may cause people to lose their inhibitions and/or release violent tendencies, and thus users cannot be fully blamed for their actions. In other words, drunkenness may give people an excuse for violence, 
despite whether or not actual pharmacological effects exist (see Gelles and Cornell, 1990, and Fagan, 1990). Finally, there is the "third factor" theory in which there exists some unknown common cause that results in both drinking and violent behaviors (see Fagan, 1990).

There may also be a link between illegal drugs and violence, although the literature supporting this notion is mixed. For example, when the perceived drug use of offenders is reported by the victims of violent crimes, the offender was reported to be under the influence of drugs 8 to 10 percent of the time (Bureau of Justice Statistics, 1993). The Bureau of Justice Statistics (1988) reports that about 25 percent of violent offenders claim they were under the influence of drugs at the time of the offense. This study also reports that jail and prison inmates are much more likely to use drugs than the general population. Another source of uncertainty regarding the link between drugs and violence concerns the possible biological effects of drugs. It is known that any biological effects differ by drug type and amount of use. For example, short-term use of marijuana, morphine and opium may inhibit aggressive behavior in humans, while long-term use can alter the nervous system in a way that actually promotes tendencies towards violence (National Research Council, 1993). Amphetamines, LSD, PCP and cocaine in small doses tend to increase aggressive behaviors, but this link may be an indirect result of the distortions in the interpretation of social signals by the users. (See Fagan, 1993 and Goldstein, 1985). In general, not much is yet known about the relationship between drugs and violence. Including drugs in this study may help to shed some light on the nature of this connection.

\section{RELATED STUDIES}

In an earlier paper, (Markowitz and Grossman, 1998), we examine the effects of alcohol regulation on violence aimed at children. Using the 1976 Physical Violence in American Families survey, we show that increasing the beer tax is an effective policy tool to reduce both the 
probability and frequency of violence towards children. In addition, we show some evidence that restrictions on the availability of alcohol may decrease violence. This current study expands upon our previous work on the effects of alcohol regulation on child abuse in three ways. First, we add data from another comparable survey conducted nine years later: the 1985 Physical Violence in American Families survey. The additional survey is useful because it is allows for a comparison of the effects of alcohol regulation over time, and it allows the years to be pooled and state fixed effects added. Fixed effects are important in determining whether the effects of the state-level alcohol regulation variables in the cross sections are reflecting unobserved state sentiment towards regulation and violence rather than true policy effects. Second, we perform the analyses separately for mothers and fathers. Third, we estimate structural as well as reduced form models. In the former, violence depends on an endogenous measure of alcohol consumption, while in the later it depends on exogenous measures of alcohol regulation.

Currently, there are no other studies in the economic literature on alcohol and child abuse. In fact, there are very few studies on any aspect of domestic violence at all. The most notable economic studies on domestic violence are by Long, et al. (1983), Tauchen, et al. (1991), and Farmer and Tiefenthaler (1997). These papers all focus only on spousal abuse and model violence as a good which can be bought or avoided with income transfers. One drawback of these studies is that the models are not applicable to instances of child abuse. The models in these papers assume that the victim has a choice to be in the relationship or not. In reality, this choice is not always available, especially for young dependents. In addition, such dependents generally have little or no income to transfer as a means of avoiding violence. Finally, there are many other factors involved in the propensity to commit violence. As previously discussed, alcohol in particular plays a major role and should not be left out of any model dealing with domestic violence. We outlined a simple framework for analysis in our earlier paper. The theoretical framework presented below formalizes 
the ideas discussed therein and presents a framework that is appropriate for the case of violence aimed at children.

\section{ANALYTICAL FRAMEWORK}

The model of domestic violence utilized here is derived from Long et al. (1983) and Becker (1968). The model is as follows: Equation 1 shows that a perpetrator's choice problem is to maximize a utility function which depends on $\mathrm{V}$, a good representing violence, consumption of alcohol (A), and consumption of all other goods (C). More appropriately, gains from violence, such as control over the victim or stress relief, should be in the utility function, but for simplicity violence will enter directly. ${ }^{2}$ Note that violence can positively or negatively affect utility. 1) $\quad \mathrm{U}=\mathrm{u}(\mathrm{V}, \mathrm{A}, \mathrm{C})$.

Violence is produced by time spent engaged in violence (Tv), alcohol consumption (A), and is also affected by $\alpha$ which represents efficiency in producing violence. ${ }^{3,4}$

2) $\quad V=v(T v, A, \alpha)$.

It is assumed that $\partial \mathrm{V} / \partial \mathrm{Tv}>0$. Alcohol enters the production function in that alcohol consumption can result in a physical reaction that makes the user more prone to violence or that makes it easier to commit a violent act, therefore, $\partial \mathrm{V} / \partial \mathrm{A}>0$.

As previously discussed, alcohol and violence may be linked not only through the chemical effects of alcohol, but also by the notion that alcohol serves to reduce the probability of the offender having to face consequences by creating a viable excuse for the behavior. That is, the perpetrator may face costs of his actions only if caught. These costs can be monetary costs such as legal fees, fines, or lost wages due to prison sentences and can be accounted for in the budget constraint of the perpetrator. Non-monetary costs may include the dissolution of the relationship, or loss of respect by the victim, family members or friends. For simplicity, we focus on the probability of facing 
monetary costs. ${ }^{5}$ The term $\mathrm{P}$ represents the probability of facing monetary costs and is represented by:

3) $\quad \mathrm{P}=\mathrm{p}(\Pi, \mathrm{A})$,

where $\Pi$ represents the part of the probability that is unaffected by alcohol use, $\mathrm{A}$ is alcohol consumption and $\partial \mathrm{P} / \partial \mathrm{A}<0$.

Considering the possibility of monetary losses gives two possible budget constraints faced by the perpetrator:

4a) $\quad \mathrm{I}=\mathrm{C}^{\mathrm{NL}}+\mathrm{PaA}+\mathrm{wTv} \quad$ when no monetary costs of violence are faced and

4b) $\quad \mathrm{I}=\mathrm{C}^{\mathrm{L}}+\mathrm{PaA}+\mathrm{wTv}+\mathrm{L}(\mathrm{Tv})$ when costs are imposed.

The term I represents income, Pa represents the monetary price plus travel and time costs of obtaining alcohol, and $\mathrm{w}$ is the wage rate which is meant to represent the opportunity cost of spending time engaged in violence. The monetary costs of violence are represented by the loss function $\mathrm{L}(\mathrm{Tv})$. The losses are a function of the time spent in violence and it is assumed that losses increase as the time spent in violence increases. $\mathrm{C}^{\mathrm{NL}}$ and $\mathrm{C}^{\mathrm{L}}$ denote other consumption when there is no loss and when there is loss resulting from violence, respectively. By design, $\mathrm{C}^{\mathrm{NL}}>\mathrm{C}^{\mathrm{L}}$ since $\mathrm{L}(\mathrm{Tv})$ is positive. The price of other consumption is normalized to 1 for simplicity.

Substituting equations $2,3,4 \mathrm{a}$, and $4 \mathrm{~b}$ into 1 yields an expected utility function:

5) $\quad \mathrm{EU}=1-\mathrm{p}(\Pi, \mathrm{A}) * \mathrm{U}[\mathrm{v}(\mathrm{Tv}, \mathrm{A}, \alpha), \mathrm{A}, \mathrm{I}-\mathrm{PaA}-\mathrm{wTv}]+$ $\mathrm{p}(\Pi, \mathrm{A}) * \mathrm{U}[\mathrm{v}(\mathrm{Tv}, \mathrm{A}, \alpha), \mathrm{A}, \mathrm{I}-\mathrm{PaA}-\mathrm{wTv}-\mathrm{L}(\mathrm{Tv})]$.

Equation 5 is the expected utility function that a perpetrator maximizes. Maximization with respect to the inputs in the production of violence yields first order equations that equate the expected marginal benefits of time spent in violence to the expected marginal costs of time spent in violence, and the expected marginal benefits of alcohol consumption to the expected marginal costs of 
alcohol consumption. ${ }^{6}$ The first order conditions imply the following reduced form demand equations:

6) $\quad \operatorname{Tv}=\mathrm{tv}(\mathrm{Pa}, \mathrm{w}, \mathrm{I}, \Pi, \alpha)$

7) $\quad \mathrm{A}=\mathrm{a}(\mathrm{Pa}, \mathrm{w}, \mathrm{I}, \Pi, \alpha)$

Substituting equations 6 and 7 into equation 2 gives:

8) $\quad \mathrm{V}=\mathrm{v}(\mathrm{Pa}, \mathrm{w}, \mathrm{I}, \Pi, \alpha)$.

Equation 8 is the reduced form model of the amount of violence supplied by the perpetrator and is the equation that will be estimated by regression techniques in this paper. Equation 8 is the main focus of this paper because the estimation of this equation will show the direct effects of increases of the price of alcohol and other regulatory measures on violence. A secondary focus of this paper is the structural model as given by equation 2 . This is the equation which relates alcohol consumption to violence directly. A positive coefficient on the measure of alcohol consumption would indicate a positive relationship between consumption and violence.

Since violence is a behavior that many people do not engage in, the model as presented above can predict values of zero for the optimal time spent in violence and for violence. Clearly, the marginal utility of violence must be positive for there to be any time spent in violence. Even if this is the case, the optimal time input will equal zero if the expected marginal benefit of time spent in violence evaluated at $\mathrm{Tv}=0$ is smaller than or equal to the expected marginal cost of time spent in violence also evaluated at $\mathrm{Tv}=0$. Given that it is optimal to allocate no time to violence but optimal to consume some alcohol, violence itself will be zero if $\mathrm{v}(0, \mathrm{~A}, \alpha)=0$ and positive otherwise. When no time is allocated to violence, alcohol consumption may have to exceed a threshold quantity, which can vary among persons, for violence to be positive. 
The same corner solution with $\mathrm{Tv}=0$ and $\mathrm{v} \geq 0$ occurs in a model in which violence is a negative source of utility. This suggests that a framework in which violence is a positive source of utility and can be increased by allocating time to its production is only one way of getting to a reduced form equation such as equation 8. A framework in which violence is a negative source of utility and a negative by-product of the consumption of alcohol provides an alternative justification of equation 8. Thus, the empirical analysis of equation 8 is not meant to test the validity of our specific model; rather the theoretical model is used as a means to reach equation 8 . The nature of the corner solution just outlined also suggests that the probability of committing violence, rather than the quantity of violence, can be treated as the outcomes in equations 2 and 8 .

\section{$\underline{\text { V. DATA }}$}

Data on violence aimed at children come from the 1976 and 1985 Physical Violence in American Families (PVAF) surveys. These surveys were designed to collect information about violence in the home and have detailed information on how conflicts are resolved. The 1976 data consist of a nationally representative sample of 2,143 married or cohabiting individuals. Of these individuals, 1,147 have children ages 3-17 living at home and thus comprise the sample examining violence towards children. ${ }^{7}$ The 1985 data are a nationally representative sample of 4,990 individuals who are either married or cohabiting, are single parents living with children under 18, or are individuals who had been married or cohabiting within the past two years. Included in this total are 4,032 individuals in the initial cross section and 958 individuals in an oversample of states. ${ }^{8}$ Of the 4,990 individuals in the cross section and state oversample, 2,675 have children ages 0-17 living at home.

\section{A. Dependent Variables}


Measures of domestic violence in the PVAF survey are collected by use of the "Conflict Tactic Scale" (CTS) developed by Straus and Gelles (1990). The CTS gathers information on the number of times in the past year a respondent has committed or has been the victim of a violent act. The dependent variable, termed the "severe violence" indicator, is a dichotomous indicator which equals 1 if the respondent committed any of the following acts towards the child in the past year: kicked, bit or hit with fist; hit or tried to hit with something; beat up the child; burned or scalded him/her (1985 survey only); threatened with a gun or knife; or had used a gun or knife on the child. ${ }^{9}$ These acts were chosen because they have potential to seriously injure a child, and the designers of the CTS identify these acts as most closely resembling what is commonly thought of as child abuse. Eighteen percent of women in the 1976 sample and 10.1 percent of men responded that they had committed at least one of these acts in the past year. In the 1985 data, 11.4 percent of women and 9.4 percent of males had committed at least one severe act of violence. Hypothesis tests of the proportions by gender reveals that females are more violent than men in both years, but the null hypothesis can only be rejected at the 10 percent level in the 1985 sample.

It can be argued that the act of hitting or trying to hit with something can be considered as punishment rather than representing an abusive or violent act (Straus and Gelles, 1990). For example, hitting the child with a belt or a hair brush is a common way to punish a child but hitting with a frying pan would be considered violence. Unfortunately, there is no way to distinguish between responses that were meant as punishments or as violence. Models of the severe violence indicator were tested with and without the act of hitting with an object, but results were very similar. Henceforth, only the violence indicator inclusive of this act are reported.

Other variations on the measure of violence were also tested. Less severe acts of violence were included, such as throwing something at the child and pushing grabbing or shoving the child. Adding these additional acts of violence do not alter the conclusions of this paper any. In addition, 
models were tested which include these less severe acts of violence as well items which represent verbal aggression such as threatening to hit or throw something at the child and throwing, smashing, hit or kicked something. Again, results were very similar to those presented below.

Even though the survey question gathers information on the number of times in the past year each act of violence had been committed, this information is not used because of the ambiguity regarding the question. The wording does not allow for a distinction between specific acts of violence that occurred on different occasions or occurred along with other types of violence on the same occasion. For example, a value of " 2 " could mean that the respondent hit the child twice in the past year, implying separate occasions. Alternatively, the same value could mean that the respondent hit the child once and hit the child with an object once, perhaps during the same incident. Any variable constructed on the number of acts would represent a combination of intensity and frequency of violence thus making interpretation difficult. This problem prevents the utilization of techniques such as tobit or any of the models for count data from being meaningful.

\section{B. Reliability of the Data}

One criticism of the Physical Violence in American Families survey focuses on the reliability of the respondents' answers to the occurrence of violence. The survey seeks to gain information about sensitive and possibly deviant types of behavior that often arouses antagonism, high refusal rates and distorted answers from the respondents, thereby bringing into question the reliability of the results. The principal investigators of the survey discuss this criticism at length. (See Straus and Gelles, 1990 for complete discussion of this issue.) First, they claim that the antagonistic aspects are minimized by presenting the questions in the context of resolving family conflicts. The question on conflicts between parents and children begin with resolution tactics such as "discuss the issue calmly" which are generally viewed as positive methods of dealing with 
problems. The scale gradually increases to questions about more socially unacceptable behavior. Through this method of getting to the violence questions, the respondent has first been given a chance to give the "socially correct" answers and is less apprehensive about discussing incidence of violence.

Currently, the CTS seems to be the best available technique for collecting truthful information on domestic violence and has been used in over 200 studies to date (see Straus and Gelles, 1990). Nevertheless, because of the potential for underreporting violence, the dependent variables are considered to be conservative estimates of violence. This poses no problem for the conclusions since so long as the measurement error in the dependent variable is random, measurement error only serves to raise the standard errors leaving the coefficients as unbiased estimators. However, if for example, drinkers systematically underreport violence, then the coefficient on the beer tax will be biased towards zero.

A related criticism is how well the Physical Violence in American Families survey reflects the reported national incidence of violence aimed at children. It is difficult to compare the estimates of violence aimed at children from this survey with those collected from other sources. The most commonly cited source is the National Study on Child Neglect and Abuse Reporting as conducted by the American Association for Protecting Children (AAPC). Their data represent cases of physical and sexual abuse or neglect and come mainly from Child Protection Services agencies around the country. This implies that cases of abuse must be reported before they can get into the national statistics, but unfortunately a large proportion of cases go unreported. In 1976 (the earliest year of data available) the AAPC estimates that 669,000 children or 10.1 children per thousand were abused or neglected (American Association for Protecting Children, Inc., 1986). The same number for 1985 is $1,928,000$ children or 30.6 children per thousand. The Physical Violence in American Families survey estimates that about 5.8 million children or 86.4 children per thousand 
who lived with both parents were the victims of severe violence in 1975. In 1985, of all children, almost 6.9 million or 109.6 children per thousand were physically abused.

\section{Independent Variables}

\section{i. Alcohol Control Variables}

The price of alcohol is measured by the real (1982-1984 dollars) state excise tax rate on a case of beer (24 12-ounce cans) as reported by the Beer Institute's Brewers' Almanac. This measure was chosen because beer is the most commonly consumed alcoholic beverage and because taxes, rather than prices, are directly set by policy makers. The 1976 survey is conducted in the first quarter of 1976, but pertains to violence in the past year. Therefore, the beer tax is taken as a simple average of the state excise tax rates that existed in the four quarters of 1975 . The 1985 survey was conducted during the summer of 1985 . Therefore, the tax on beer is taken as an average of the tax rate that existed in the first two quarters of 1985 and the last two quarters of 1984.

A variety of measures are constructed to represent the availability and prevalence of alcohol in each state. First, variables representing restrictions on beer advertising are included in the models. These variables come from Modern Brewery Age Blue Book (various years). Specifically, dichotomous indicators are included for whether a state prohibits each of the following: price advertising of beer in newspapers and magazines; billboards advertising beer; window displays of signs, packages and products in liquor stores; and consumer novelty giveaways. Restrictions on the first three will serve to make the full price of beer higher due to increased search costs. Bans on consumer novelties also serve to raise the full price of beer because novelties act as discounts in kind.

Retail availability factors in to the full price of alcohol faced by individuals. To capture the availability effects, three measures are employed. The first is a dichotomous indicator for whether or not grocery stores can sell beer. ${ }^{10}$ Data for grocery store sales come from Jobson's Liquor 
Handbook (various years). Secondly, the percentage of each state's population living in counties dry for beer as given by the Brewers' Almanac are included. With larger percentages of populations living in dry counties, travel time to obtain alcohol increases, adding to the full price of alcohol. In addition, this measure serves to capture some of the unobserved state sentiment towards drinking which may be reflected in the drinking habits of the state's residents. Finally, the number of retail outlets per 1,000 population that are licensed to sell alcoholic beverages for on-premise or offpremise consumption is included. These data come from Jobson's Liquor Handbook, (various years).

\section{ii. Illegal Drugs}

The price of one gram of pure cocaine is included in some models. Prices are derived from the System to Retrieve Information from Drug Evidence (STRIDE) maintained by the Drug Enforcement Administration (DEA) of the U.S. Department of Justice. The reported prices vary by weight and purity, so the price of one gram of pure cocaine is obtained from a regression of the natural logarithm of purchase price on the natural logarithms of weight and purity, dichotomous variables for each city and year except one, and interactions between the year and variables representing eight of the nine Census of Population divisions. (See Grossman and Chaloupka, forthcoming, for further details.) Since 1977 is the earliest year the cocaine data are available, the 1976 violence data are matched with cocaine prices from 1977.

The prices of marijuana is generally unavailable. However, by 1976, some states had decriminalized the possession of small amounts of marijuana for personal use, thus effectively lowering the full price of its use. Therefore, a dichotomous indicator for whether a state decriminalized marijuana is included in some models. Information on decriminalization comes from the Sourcebook of Criminal Justice Statistics (Bureau of Justice Statistics, 1984). 


\section{iii. Individual Characteristics}

Literature on domestic violence from other disciplines provides insight into the personal characteristics that lead to a predisposition towards violence. (See Gelles and Cornell, 1990 for profiles of domestic abusers and their victims.) People who were abused by their parents or saw their parents fight a lot, for example, are more likely to be violent towards their own children. In order to proxy for these two factors, dichotomous indicators are included to represent whether or not the respondent's parents used physical punishment on the respondent and if the respondent's parents hit or threw things at each other during the respondent's teenage years.

Three measures of stressful life styles are also included. The first measure is the number of children at home. More children can lead to more stress as well as more opportunities for violence. The second is a dichotomous variable indicating whether the respondent talks to other people about personal family problems in order to help relieve stress. There are differences in the wording of this question in the two survey years so this variable is omitted from models which pool the 1976 and 1985 cross sections. The third is a direct measure of stress. In the 1976 data, this question takes the form of the number of specific stressful events encountered in the past year. These events include trouble at work, health problems, money problems, and problems with family members. In the 1985 data, the question designed to measure stress simply asks how often the respondent felt nervous or stressed in the past year. The answers can range from never to very often. Because of the difference in the form of the stress question, this measure is also omitted from the pooled models.

Socio-economic and demographic characteristics may also play a role in determining an individual's propensity towards violence. Three indicators of race are included; black, not Hispanic; Hispanic; and other race. The missing category is white, not Hispanic. The respondent's 
age, gender, education, income, occupation, employment status, religion, frequency of religious service attendance (in the 1976 cross section only), and an indicator for whether the respondent is a single parent (in 1985 only) are included in all models. In addition, the child's gender and age are included in the models. Any missing values are coded at the mean of the known observations. The variables with the largest number of missing variables for the 1976 data are whether the respondent's parents hit him or her as a teenager (16 percent of the sample missing) and whether or not the respondent's parents hit each other when the respondent was a teenager (17 percent missing). The rest of the socioeconomic and demographic variables in the 1976 data have relatively few missing variables with amounts ranging from 0 to 6 percent missing. The percentage of the sample with missing values is much smaller for the 1985 data and ranges from 0 to 3 percent missing. Results on the regulatory variables are not sensitive to the deletion of regressors with missing values.

One potential problem with many of the individual characteristics is that they may be correlated with the error term in the violence equations. That is, there may be some unmeasured factor that affects the outcomes of both the propensity to commit violence and the individual characteristics. The characteristics most likely to be endogenous are the number of children at home, the indicator for whether people talk to others about their problems, the measures of stress, the respondent's education, income, occupation, employment status, religiosity and single parent status. The coefficients on these potentially endogenous variables are likely to be biased if not instrumented for. However, including these variables will not bias the coefficients on the state-level regulatory variables (the variables of interest in this paper) so long as the individual and state-level variables are not correlated. Models were tested that exclude the above mentioned variables from the cross sections. The results are not shown, but the coefficients on the beer tax and the other 
price, availability and advertising measures for both males and females are very similar to those that include the potentially problematic individual characteristics.

\section{ESTIMATION AND RESULTS}

Equation 8 serves as the basic equation for estimation. The probability of participation in violence is specified as a probit function and depends on the full price of alcohol, the price of illegal drugs and the characteristics of the parent, the child, and the household.

Equation 8 is also estimated separately for males and females. This is done because of different observed drinking and violence patterns of men and women. For example, studies have shown that men are more likely than women to become violent when drinking (see Fagan, 1990 and the references he cites). In addition, some studies have shown that females drink less than males and are more price sensitive (Kenkel, 1993, and Moore and Cook, 1995). Likelihood ratio tests on all of the independent variables in each of the two surveys reveal that the two sexes should not be pooled. ${ }^{11}$ In addition, models which include interaction terms between gender and all the independent variables show that coefficient on the interaction for the beer tax (the coefficient of interest in this paper) and gender is insignificant in the 1976 data but significant in the 1985 data. This implies that at least in the 1985 data, there are differences in the tax coefficients for males and females.

Two basic models are estimated. The first model contains the state excise tax rate on beer and the individual characteristics. The second adds to the first all the price, advertising, and availability measures. There are a few potential problems with the two models presented. First, the specifications which include only the beer tax and the individual characteristics are prone to omitted variable bias if the drug, advertising or availability measures are predictors of violence. Omitted variable bias is a more serious problem in probit models than in ordinary least squares because even 
if the omitted variables are uncorrelated with the included variable, the coefficient on the included variable can still be inconsistent. (See Greene, 1993 and Yatchew and Griliches, 1985 for a discussion of this issue.) However, including all the relevant control variables may lead to the problems of multicollinearity. This problem may arise because states which heavily restrict advertising are more likely to restrict availability. Also, states tend to simultaneously enact laws regulating different forms of advertising.

Another potential problem is that the effects of state-specific regulatory variables will reflect unobserved state sentiment towards violence and/or drinking. This issue is addressed by testing models which pool the two cross sections, thus allowing for state fixed-effects to be added. These results are discussed below. A final problem is that Moulton (1990) has shown that standard errors of coefficients of aggregate variables in micro regressions are biased downward if the disturbance terms in the regressions are positively correlated among persons who live in the same area. Thus, models were tested which correct the standard errors for intra-state correlation according to Huber (1967). Making this correction does not alter the conclusions of this paper and in many cases, serves to lower the standard errors of the coefficients. The results below are shown with the uncorrected standard errors.

All reduced form estimates display the effects of the beer tax, drug prices, and alcohol availability and advertising variables on the probability of violence. Given that the measures of alcohol control are the variables of interest, the individual characteristics included in each model are not shown in the tables. Results of the individual characteristics are discussed below. Each table lists the probit coefficients first, the t-statistic on the coefficients in parentheses, and the marginal effects of the coefficients in bold italics. The marginal effects shown for the dummy variables are calculated by $\Phi\left(\mathrm{X}_{1} \mathrm{~b}\right)-\Phi\left(\mathrm{X}_{0} \mathrm{~b}\right)$, where $\Phi$ is the cumulative normal density, and $\mathrm{X}_{0}$ and $\mathrm{X}_{1}$ are vectors of the means of the independent variables except that the value of the dummy variable of 
interest equals 0 and 1, respectively. Marginal effects for continuous variables are calculated at the mean of the independent variables.

\section{A. The Cross Sections by Gender \\ i. Females}

Table 1 shows the effectiveness of the tax on beer in reducing the probability of severe violence committed by female respondents in the 1976 and 1985 samples. The coefficients on the beer tax are negative and significant. ${ }^{12}$ Beginning with the 1976 sample, the results show that a one percent increase in the tax on beer will decrease the probability of violence by about 0.33 percent (which is a simple average of the elasticities of the two models). Tax elasticities are calculated by multiplying the marginal effects by the ratio of the average tax to the proportion of respondents who are violent. $^{13}$

Column 2 shows that the number of outlets licensed to sell liquor is positive and significant indicating that increasing the number of outlets by 1 per 1000 population will increase the probability of severe violence towards children by about 6 percentage points. In addition, increases in the percentage of a state living in dry counties will reduce severe violence. The other availability measure, the prohibition of the sale of beer in grocery stores, does not explain any of the variation in violence, nor do the drug prices or most of the advertising restrictions. The prohibition of window displays is the only advertising measure that is negative and significant. Multicollinearity among the advertising variables may make the individual effects of the variables indistinguishable from each other. Therefore, the last rows in each table show a chi-squared test of the availability and advertising variables each as a set. However, the results in Table 1 indicate that the availability and advertising measures as sets are not statistically different from zero. 
The female respondents in the 1985 sample are also responsive to the state excise tax on beer. Estimates in columns 3 and 4 in Table 1 show that the beer tax is effective in reducing violence committed by women, with an average elasticity of -0.13 . The results also show that severe violence by women in 1985 is sensitive to the price of cocaine (at the ten percent level in a two-tailed test), whereas the same did not hold true for females in 1976. Another contrast to the 1976 data is that in 1985 , the availability and advertising measures appear to have no impact on the probability of severe violence committed by women in 1985. This result is surprising given the larger sample size in the 1985 data.

Caution must be exercised in comparing the 1985 and 1976 cross sections because of the different composition of the two samples. The main difference between the two surveys is that respondents who are single parents and parents with children under age three are not included in the 1976 data. In order to make a more direct comparison to the 1976 cross section, models were tested with the 1985 sample that exclude mothers with infants and mothers who are single parents (results not shown). In these limited specifications, the coefficient on the beer tax is negative but not statistically significant. This is in direct contrast to both the 1976 results and the 1985 full sample results. One possible explanation for the observed inability of the beer tax to reduce violence in the limited 1985 sample is that it is inappropriate to restrict the sample. For example, it is possible that the 1976 sample may include married women who share the same characteristics as the single women in the 1985 sample. The national divorce rate was much higher in 1985 than in 1976. There were 128 divorced persons per 1,000 married persons versus 69 divorced persons per 1,000 married persons in 1976, (Bureau of the Census, 1989) so it is plausible that the 1976 sample includes women who would otherwise be divorced were it 1985. Since the probability of divorce was much lower in 1976, these women are more likely to be married and included in 1976 when 
during later time period they may have been part of a single parent sample. Unfortunately, there is no way to test this hypothesis with these data.

\section{ii. Males}

Table 2 shows results from the 1976 and 1985 cross sections for males. The issue of the presence of single men in the 1985 sample is not problematic because single fathers make up only 4.6 percent of the sample of males. There are 214 fathers of infants ( 20 percent) in the 1985 male sample, but the results are the same regardless of the inclusion of these fathers.

In the 1976 cross section, the coefficient on the beer tax is negative and significant at the 10 percent level in the model that includes only the beer tax and the individual characteristics. However, this effect is greatly reduced when the other control variables are added. The coefficients on the beer tax in the 1985 data are surprisingly positive and significant in both models. We have no explanation for this last result.

Increases in the tax on beer seems to be ineffective in reducing the probabilities of violence committed by males. In addition, there is no evidence that the other regulatory variables may be any more effective. In both years, almost none of the drug prices, availability measures or advertising variables are statistically significant in reducing the probability of violence. However, the signs of the availability measures are as anticipated in both years.

\section{B. 1976 and 1985 Pooled Results}

There are two possible problems with the cross sectional analyses. The first is that small sample sizes may not allow for precise estimates of the coefficients. A second problem is that it is impossible to control for unobserved state effects or sentiments that may influence alcohol regulation and violence rates. Pooling the 1976 and 1985 cross sections allows both of these issues 
to be addressed. By pooling, sample sizes will increase, and unobserved state effects can be controlled for by including dummy variables for all of the states except for one.

Table 3 shows the pooled results for females and males. It is unclear whether it is appropriate to make the 1985 female sample similar to the 1976 sample in terms of demographics by omitting respondents with infants and respondents who are single mothers. However, based on the argument that some women who were married in 1976 may not have been were it 1985, it seems more appropriate to leave the 1985 sample as is and not exclude any observations. Excluding both single women and women with infants alters the findings slightly for women, for in this case the beer tax is negative and significant in all models regardless of the inclusion or exclusion of the state dummy variables (results not shown). In addition, when compared to the results in Table 3 , the magnitude of the tax effect becomes larger when state dummies are included and smaller when the state dummies are excluded.

A few words of caution must be put forth in relying on the pooled models. First, some observations had to be deleted from the regressions that include state dummies because certain states had only a few respondents in them. If it happens that those few respondents all have the same outcome for violence then the predicted probability of violence based on those states would have to be the same as the outcome. The probit coefficient must then approach plus or minus infinity. In order to eliminate this problem, individuals in states where the respondents all had the same response to the violence question were omitted from the regressions.

Next, one may question the validity of pooling two years ten years apart. It is quite plausible that the slope coefficients for many if not all of the variables had changed over the sample period. A likelihood ratio test for pooling is shown in Table 3. In all cases, the tests reveal that the two years should not be pooled. However, this result is being driven by the individual, household, and child characteristics, for in models that include interaction terms between all the independent 
variables and a dummy for 1985 , there is evidence that the coefficient on the real beer tax does not change between the two years. This result holds for the sample of women, in models that include and exclude the state dummies. For men, the same conclusion holds only for the models that include the state dummies. See the section on males below for further discussion of this result. One can reject the hypothesis that the interactions between the time dummy and the individual, household, and child characteristics are equal to zero. Technically, these interactions should be included in the models in Table 3, but their inclusion or exclusion does not alter the results of the alcohol and drug regulatory variables so these interactions are omitted.

\section{i. Pooled Females}

For females, the cross sectional analyses showed separately that increases in the beer tax would reduce the probability of violence towards children. Not surprisingly then, the pooled sample exclusive of the state fixed effects shows the same results (see columns 1 and 2 of Table 3 ). The tax elasticity is -0.20 in the model in column 1 and is -0.16 in the model in column 2 for an average elasticity of -0.18 . This average is comparable to the average elasticity derived from the two cross sections, which is -0.23 .

It is interesting to note that pooling the sample and thereby increasing the sample size does not result in measurable effects of the advertising or availability measures on violence, even thought in the 1976 cross section both the percent dry and the number of licensed outlets were significant. Contrary to what was expected a priori, the prohibition of sales of beer in grocery stores is significant in increasing the probability of violence.

When the state dummies are added to the models in columns 1 and 2 in Table 3, the coefficients on the beer tax remain negative, but in general, lose significance (see columns 3 and 4). However, the magnitude of the coefficients and marginal effects are largely unaffected by the 
inclusion of the state dummies. Given that as a set, the state dummies are not significant, these results most likely reflect collinearity between the state dummy variables and the state-specific tax on beer . In other words, state dummies do not capture any unobserved state sentiment towards drinking or violence, rather they act as irrelevant included variables that are correlated with the beer $\operatorname{tax}$.

\section{ii. Pooled Males}

For males, the results from the two cross sections show that an increase in the beer tax has either no effect or a positive effect on the probability of violence. The pooled results tell a slightly different story. The coefficients on the beer tax in the severe violence equations which excludes the state dummies (columns 5 and 6 in Table 3) are insignificant with the sign varying depending on the other included variables. However, these coefficients are biased. This is because in a model which includes the beer tax interacted with the dummy for 1985, the coefficient on the beer tax is negative and significant and the interaction term is positive and significant. This indicates that there are difference in the slope coefficients in the two years and the models should not be pooled. By contrast, including the state dummies renders an interaction coefficient that is insignificant implying that once unobserved state effects are controlled for the two years can be pooled. In sum, because of the potential statistical inappropriateness of pooling the data, it is difficult to draw a conclusions about the propensity of increases in the beer tax to reduce violence aimed at children by their fathers. This is an area for further research.

\section{ALCOHOL CONSUMPTION}

The theory on which this study is based rests on the assumption that alcohol consumption is positively related to violence. The Physical Violence in American Family surveys contain some measures of alcohol consumption, thus allowing for an estimation of this structural relationship. 
Estimates of the structural model as given by equation 2 are shown in Table 4 . In this table, the measure of alcohol consumption, drunkenness, is treated as both exogenous and endogenous. The theory presented in this paper strongly suggests that alcohol consumption should be treated as endogenous for the following reasons: First, the first order equation for alcohol consumption shows that consumption is partly determined by time spent in violence. ${ }^{14}$ Intuitively, this reverse causality can be explained by the argument that if a person is planning on being violent, they may drink in order to lower the probability of facing monetary costs. Secondly, alcohol consumption may be correlated with the error term in the violence equation if there are some unmeasured characteristics that makes people both drink and be violent. In this case, alcohol consumption would still be endogenous and should be instrumented for in the violence equations. Linear probability models with standard errors corrected for heteroskedasticity are used to estimate the structural equations. ${ }^{15}$ The two-stage least squares equations correspond to Heckman and MaCurdy's (1985) simultaneous equations linear probability model.

In the 1976 survey, the only question on alcohol consumption asks how often the respondent gets drunk. The answers are categorized into never, rarely, occasionally, often, very often, or almost always. Note that this question does not put a time frame on drunkenness. Since violence and beer taxes are in regards to the past year, the question on drunkenness in 1976 may or may not be a good representation of alcohol consumption in the past year. In 1985, however, the same question is asked in regards to the past year, and this time the answers are coded as the actual number of times the respondent got drunk. In estimating the structural equation, the responses for how often a parent gets drunk are transformed into a dichotomous indicator in both years of the survey. This is done in order to allow the results for the 1976 data to be compared to and pooled with the 1985 data. A respondent in the 1976 data was given a zero if he or she reported getting 
drunk either never or rarely, and was given a one otherwise. Five percent of the females in 1976 received a value of one for drunkenness whereas 16 percent of the males were given a value of one. A respondent in the 1985 data was given a zero if he or she reported getting drunk either zero, one, or two times in the past year and a one if the response was more than two times. Six percent of females in 1985 and 15 percent of males in 1985 reported getting drunk more than 2 times in the past year. Categorizing less than three incidents of drunkenness as approximate to never or rarely being drunk is an arbitrary assignment. However, increasing the number of times classified as never or rarely to three times in the past year does not alter the results presented.

Table 4 shows the results of the dichotomous indicator of drunkenness for females and males in the 1976 data, the 1985 data and in pooled models. ${ }^{16}$ In this table, columns 1 and 3 treat drunkenness as exogenous and columns 2 and 4 treat drunkenness as endogenous. In columns 2 and 4, the only instrument is the state excise tax on beer. Models were tested which include all the regulatory variables as instruments, however, these estimates are unreliable because the set of regulatory variables do not serve as good instruments. Chi-squared tests of the set of regulatory variables are only statistically significant for females when the years are pooled. In all other models, the chi-squared is insignificant indicating that the bias in the TSLS estimates approach that of OLS. By contrast, the coefficients on the state excise tax on beer in the first stage estimates that omit the other regulatory variables are negative and statistically different from zero for females in all years, and for males in 1985 and the pooled model.

Focusing first on women in columns 1 and 2 of Table 4, the results show that the dichotomous indicator of drunkenness is positively related to the probability of violence in both years. The coefficients in the OLS estimates are positive but are not statistically significant. The coefficients in the TSLS models are also positive, and the 1976 and pooled values are significant. A 
Hausman test reveals that exogenity can only be rejected in the pooled sample of women, but the estimates for this sample are likely to be the most reliable given its size.

The coefficient on drunkenness in the OLS models can be interpreted as the difference in the probability of violence by those who get drunk often and those who do not. In the pooled models for females, this differences is about 6 percentage points, indicating that those who get drunk often are about 6 percentage points more likely to be violent than those who do not get drunk often. In the TSLS model, the coefficient shows the effect of an increase in the predicted probability of drunkenness. According to the estimates, a one percentage point increase in the probability of drunkenness leads to a two percentage point increase in the probability of child abuse. One way to evaluate the magnitude of this effect is to note that the probability of alcohol-related violence is the product of the probability of drunkenness and the probability of violence conditional on drunkenness. If an increase in the incidence of drunkenness has no impact on the conditional probability of violence, the coefficient of the probability of drunkenness in the violence equation should be smaller than one since it would equal the conditional probability. A coefficient greater than one could result if an increase in the probability of drunkenness raises the condition probability of violence. $^{17}$

The story for males in columns 3 and 4 of Table 4 is quite different from that of females. The coefficients on drunkenness are positive in all models except in the TSLS estimate in 1985, but are always insignificant in both the OLS and TSLS estimates. The Hausman test shows that exogenity cannot be rejected in all cases, and the first stage results show that the beer tax is generally not a good instrument. Only in the pooled sample of males is the beer tax a valid instrument. 
The tax elasticity of consumption is given by the first stage results of estimation of the structural model. Using the pooled samples, the tax elasticity is -0.19 for females and -0.14 for males. These elasticities can be compared to the results of other studies. Kenkel (1993) computes a price elasticity of demand for heavy drinking (number of days with five or more drinks in the past year) and finds an estimated elasticity of -1.14 for females and -0.71 for males. Multiplying our estimated tax elasticities by the ratio of the average beer price to the average tax gives an approximation of the price elasticity. Using the average price of beer in 1982 as given by the American Chamber of Commerce Researchers Association, our price elasticities are -0.89 for females and -0.64 for males. While slightly smaller, these are reasonably close to Kenkel's estimates even though we employ a very different measure of consumption.

In summary, for females the estimates of the structural violence equation and the reduced form demand function for beer are consistent with a causal mechanism in which the price of alcohol affects violence because it affects the consumption of alcohol. The results do not indicate whether alcohol consumption is treated by parents as a means of lowering the probability of facing the consequences of committing violent acts or as a good whose consumption has negative as well as positive consequences. Furthermore, the magnitude of the alcohol consumption effect should be interpreted with caution in light of the relatively poor indicator of heavy drinking available in the survey.

\section{INDIVIDUAL CHARACTERISTICS}

Table 5 shows the results of the socio-economic and demographic characteristics of the respondent on the probability of severe violence towards children. The impacts of these variables are not sensitive to the inclusion or exclusion of the drug prices, and alcohol advertising and availability measures, and therefore, results from the models which exclude the availability and 
advertising variables are shown. In general, the variables that affect the probability of violence committed by women are the same as those for men. Primarily, if as a teenager, the respondent was hit by his or her parents, the probability of violence will increase. Females may also learn to be violent by having watched their parents hit each other (see the 1985 results for females). Race plays a role in that black women (in 1985) and Hispanic women (in 1976) are more likely than white women to be violent, while Hispanic men are less likely to be violent than white men. With the exception of females in 1976, age does not seem to affect the probability of violence. In addition, the employment status of the respondent does not have much of an effect on violence nor do the religion variables for men. Religion does play a role in determining violence by women.

Education and income both do not determine incidence of violence. These results are not surprising from an economic standpoint. The theoretical model of violence shows that an increase in the wage rate (as proxied for by income) will have an ambiguous effect on violence. This occurs because a wage increase will increase the shadow price of violence and decrease violence. But the increase in income from the wage increase will allow more violence to be purchased, leading to an ambiguous effect of a wage increase on violence. A similar story can be told for education if education is a proxy for higher wages.

For men in either year, having a female child or an older child will lower the probability of violence, while having more children at home will increase the probability. For women, only having more children at home increases the probability of violence. Finally, more self-reported stress will increase the probability of violence by women in the 1985 sample.

\section{CONCLUSION}


The main conclusion from the results presented in this paper is that increases in the state excise tax on beer will reduce the probability of violence committed by females, but have no effect on the propensity of men to be violent. These results are supported by limited evidence that alcohol consumption is positively related to violence by females, but is not related to violence by males. For females, a 10 percent increase in the beer tax will decrease the probability of violence by about 3.3 percent in the 1976 data and 1.3 percent in the 1985 data. Increases in drug prices would have no effects on violence aimed at children committed by either parent, nor would restrictions on advertising. The effect of restricted availability of alcohol is ambiguous.

According to the Bureau of the Census (1977) there were 40 million children between the ages of 3 and 17 living with both parents in 1975. If 10 percent were the victims of severe violence by their mothers ( 4 million) then a 10 percent increase in the beer tax would have lowered the number of abused children by about 129,360 . The same analysis for 1985 would result in a reduction of 57,300 children who were abused.

While increasing the tax on beer would lower violence committed by women, any policy decisions must weight the cost of raising the tax on beer versus the benefits of the reduction in child abuse. Raising the beer tax would serve to penalize people who consume alcohol but who are not violent. 


\section{REFERENCES}

American Association for Protecting Children, Inc. Highlights of Official Child Neglect and Abuse Reporting, 1984, The American Humane Association, Denver, CO, 1986.

American Chamber of Commerce Researchers Association. Inter-City Cost of Living Index. Louisville, Kentucky: ACCRA, 1982.

Becker, Gary S. "Crime and Punishment: An Economic Approach.” Journal of Political Economy, 76:2 March/April 1968, 169-217.

Beer Institute. Brewers' Almanac. United States Brewers Foundation, New York, NY, various years.

Behling, D. “Alcohol Abuse Encountered in 51 Instances of Reported Child Abuse." Clinical Pediatrics 18, 87-91, 1979.

Bureau of the Census, U.S. Department of Commerce. "Marriage, Divorce, Widowhood and Remarriage by Family Characteristics: June 1975." Current Population Reports. Government Printing Office, Washington D.C., August 1977.

Bureau of the Census, U.S. Department of Commerce. Statistical Abstract of the United States, 1989. Washington, DC, 1989.

Bureau of Justice Statistics, U.S. Department of Justice. Report to the Nation on Crime and Justice. Second Edition. NCJ-105506, March 1988.

Bureau of Justice Statistics, U.S. Department of Justice. Highlights from 20 Years of Surveying Crime Victims: The National Crime Victimization Survey, 1973-92. NCJ-144525, October 1993.

Bureau of Justice Statistics, U.S. Department of Justice. Sourcebook of Criminal Justice Statistics, 1983. Government Printing Office, Washington D.C., 1984. 
Children of Alcoholics Foundation. Helping Children Affected by Parental Addiction and Family Violence: Collaboration, Coordination, and Cooperation. New York: Children of Alcoholics Foundation, 1996.

Collins, James J. Jr. editor. Drinking and Crime: Perspectives on the Relationships between Alcohol Consumption and Criminal Behavior. The Guilford Press, New York, NY, 1981.

Fagan, Jeffrey. "Intoxication and Aggression" in Drugs and Crime: Crime and Justice, A Review of Research, Vol. 13. Michael Tonry and James Q. Wilson, Editors. The University of Chicago Press, Chicago, 1990.

Fagan, Jeffrey. "Interactions Among Drugs, Alcohol and Violence." Health Affairs, 12:4, Winter 1993, 65-79.

Famularo, R., K. Stone, R. Barnum, and R. Wharton. "Alcoholism and Severe Child Maltreatment." American Journal of Orthopsychiatry, 56, 481-485, 1986.

Farmer, Amy and Jill Tiefenthaler. “An Economic Analysis of Domestic Violence.” Review of Social Economy, 55:3, Fall 1997, 337-358.

Gelles, Richard J. and Claire P. Cornell. Intimate Violence in Families. Sage Publications, Inc., Newbury Park, CA, 1990.

Gil, D. Violence Against Children: Physical Child Abuse in the United States. Harvard University Press, Cambridge, MA, 1973.

Greene, William H. Econometric Analysis. Macmillan Publishing Company, New York, NY, 1993.

Goldstein, Paul J. "The Drugs/Violence Nexus: A Tripartite Conceptual Framework” Journal of Drug Issues, 15, Fall 1985, 493-506. 
Grossman, Michael and Frank J. Chaloupka. "The Demand For Cocaine By Young Adults: A Rational Addiction Approach.” Journal of Health Economics, forthcoming.

Huber, P.J. "The Behavior of Maximum Likelihood Estimates Under Nonstandard Conditions" in Fifth Berkeley Symposium on Mathematical Statistics and Probability. University of California Press, Berkley, CA, 1967, 221-233.

Heckman, James J. and Thomas E. MaCurdy. “A Simultaneous Equations Linear Probability Model.” Canadian Journal of Economics, 18:1, February 1985, 28-37.

Jobson's Liquor Handbook. Jobson Publishing Corporation, New York, NY, various years.

Kenkel, Donald S. "Drinking, Driving, and Deterrence: The Effectiveness and Social Costs of Alternative Policies.” Journal of Law and Economics, 36, October, 1993, 877-913.

Long, Sharon K., Ann D. Witte and Patrice Karr. "Family Violence: A Microeconomic Approach.” Social Science Research, 12, 1983.

Markowitz, Sara and Michael Grossman. "Alcohol Regulation and Domestic Violence Towards Children." Contemporary Economic Policy, 16:3, July, 1998.

Modern Brewery Age Blue Book, Norwalk, CT, various years.

Moore, Michael J. and Philip J. Cook. "Habit and Heterogenenity in the Youthful Demand for Alcohol.” NBER Working Paper No. 5152, June, 1995.

Moulton, Brent R. "An Illustration of a Pitfall in Estimating the Effects of Aggregate Variables on Micro Units.” Review of Economics and Statistics 72:2, May 1990, 334-338.

National Research Council. Understanding and Preventing Violence. Reiss, Albert J., and Jeffery A. Roth, Editors. National Academy Press, Washington, D.C., 1993. 
Pernanen, Kai. "Theoretical Aspects of the Relationship Between Alcohol Use and Crime." in Drinking and Crime: Perspectives on the Relationships between Alcohol Consumption and Criminal Behavior. James J. Collins Jr., editor. The Guilford Press, New York, NY, 1981.

Straus, Murray A. and Richard J. Gelles. Physical Violence in American families 1976 and 1985 [Computer File]. Conducted by Murray A. Straus, University of New Hampshire, and Richard J. Gelles, University of Rhode Island. 2nd ICPSR ed. Ann Arbor, MI: Interuniversity Consortium for Political and Social Research [producer and distributor], 1994.

Straus, Murray A. and Richard J. Gelles. Physical Violence in American Families : Risk Factors and Adaptations to Violence in 8,145 Families. Transaction Publishers, New Brunswick, NJ, 1990.

Tauchen, Helen V., Ann Dryden Witte, and Sharon K. Long. "Domestic Violence: A Nonrandom Affair.” International Economic Review, May 1991.

Yatchew, Adonis and Zvi Griliches. "Specification Error in Probit Models" The Review of Economics and Statistics, 67:1, February 1985, 134-139. 


\section{FOOTNOTES}

Research for this paper was supported by grant number 1 R01 AA10817 from the National Institute on Alcohol Abuse and Alcoholism to the NBER. The authors would like to express thanks to Robert Kaestner, Linda Edwards, Ted Joyce, Donald Kenkel, Helen Tauchen, Phil Cook, Jeff DeSimone, and Debbie Viola for many helpful comments and suggestions. Earlier versions of this paper were presented at a seminar at the City University of New York Graduate Center and at the annual conferences of the American Economic Association, the Eastern Economic Association and the Population Association of American. We also thank the conference participants for many helpful comments and suggestions. This paper has not undergone the review accorded official NBER publications; in particular, it has not been submitted for approval by the Board of Directors. Any opinions expressed are those of the authors and not that of NIAAA or the NBER.

${ }^{1}$ The term "child abuse" in Gil's study refers to physical violence only. This term is also commonly used to describe sexual abuse and neglect as well as physical abuse (as is the case in the next two studies cited). The terms "child abuse" and "violence towards children" are used in this paper to represent physical violence only. Other types of abuse are not considered here.

${ }^{2}$ An alternative specification would be to have a good, Z, enter the utility function directly. $\mathrm{Z}$ would represent control over the child, stress relief or the quality of the child. $\mathrm{Z}$ would be produced by violence (which could enter positively or negatively) and by other factors, such as verbal conflict resolution techniques in the case of control or the child's health and education in the case of child quality. The addition of $\mathrm{Z}$ would not change any of the predictions of the model.

${ }^{3}$ Drug use can also be considered here. Drugs will enter into the discussion in the same manner as alcohol and are therefore omitted. 
${ }^{4}$ While technically an efficiency parameter, in the reduced form, $\alpha$ is indistinguishable from taste variables.

${ }^{5}$ We assume that the probability and the size of non-monetary costs, which clearly affect the supply of offenses, are reflected by some or all of the demographic and socioeconomic variables which are used as controls in the regressions. If $\alpha$ in equation 2 is interpreted as a vector, some of the elements in this vector may affect the expected value of non-monetary costs as well as efficiency in the production of violence.

${ }^{6}$ The first order condition for the optimal time spent in violence is given by:

6а) $1-p(\Pi, A)\left[U_{V}^{N L} V_{T v}\right]+p(\Pi, A)\left[U_{V}^{L} V_{T v}\right]=1-p(\Pi, A)\left[U_{C}^{N L} w\right]+p(\Pi, A)\left[U_{C}^{L} w+U_{C}^{L} L_{T v}\right]$

and for alcohol consumption:

7a) $1-p(\Pi, A)\left\lfloor U_{A}^{N L}+U_{V}^{N L} V_{A}\right\rfloor+p(\Pi, A)\left[U_{A}^{L}+U_{V}^{L} V_{A}\right\rfloor=1-p(\Pi, A)\left[U_{C}^{N L} P a\right]+p(\Pi, A)\left[U_{C}^{L} P a\right]-\frac{\partial P}{\partial A}\left[U^{L}-U^{N L}\right]$.

${ }^{7}$ In the 1976 survey, the question on violence towards the child was not asked if the child was less than three years old.

${ }^{8}$ The state oversampling was done to increase the minimum sample sizes of many states. Accounting for the state oversample by weighting does not alter the results. All results presented are unweighted.

${ }^{9}$ The omission of the item "burned or scalded" in the 1976 data is not problematic for comparison purposes because all respondents except for one who replied yes to burned or scaled had also responded positively to at least one other item in the severe violence scale.

${ }^{10}$ Drug stores can also sell beer and liquor in some states, but this variable is not used because it is highly collinear with the indicator for grocery store sales. 
${ }^{11}$ The calculated test statistic for models that omit the availability measures is 48.00 in 1976 and is 40.07 in 1985 . The critical value for a chi-squared with 23 degrees of freedom is 35.17 at the 5 percent level and 41.64 at the 1 percent level. The calculated test statistic for models that include the availability measures is 56.27 in 1976 and is 44.13 in 1985 . The critical value for a chi-squared with 32 degrees of freedom is 45.91 at the 5 percent level and 52.67 at the 1 percent level.

${ }^{12}$ Statements concerning statistical significance of coefficients in the text are based on onetailed tests at the 5 percent level except when the direction of the effect is unclear on a priori grounds or when the estimated effect has the wrong sign. In the latter cases two-tailed tests are used.

${ }^{13}$ The average tax on beer in 1976 is $\$ 0.80$ and is $\$ 0.47$ in 1985 .

${ }^{14}$ The first term in equation $7 \mathrm{a}$ is the difference in utilities in the two states. This difference is simply the loss from violence, which is a function of time spent in violence.

${ }^{15}$ Probits were also used to estimate both stages of the structural equation. However, the resulting marginal effects of drunkenness on violence are very similar to those obtained with the linear probability model.

${ }^{16}$ Based on the results of the reduced form, the pooled results for the structural models omit state dummies.

${ }^{17}$ The marginal effect discussed above is also greater than one in a probit specification of violence that uses the predicted probability of drunkenness obtained from a first stage probit model. 
Table 1

Probit Estimates of Severe Violence by Females

1976

1985

\begin{tabular}{|c|c|c|c|c|}
\hline & (1) & (2) & (3) & (4) \\
\hline State excise tax on beer & $\begin{array}{c}-0.347 \\
(-3.36) \\
-\mathbf{0 . 0 8 2}\end{array}$ & $\begin{array}{c}-0.282 \\
(-2.43) \\
-\mathbf{0 . 0 6 5}\end{array}$ & $\begin{array}{c}-0.211 \\
(-2.19) \\
\mathbf{- 0 . 0 3 4}\end{array}$ & $\begin{array}{c}-0.189 \\
(-1.68) \\
-\mathbf{0 . 0 3 0}\end{array}$ \\
\hline Marijuana decriminalization & & $\begin{array}{r}0.307 \\
(0.54) \\
\boldsymbol{0 . 0 8 2}\end{array}$ & & $\begin{array}{c}-0.008 \\
(-0.08) \\
\mathbf{- 0 . 0 0 1}\end{array}$ \\
\hline Cocaine price & & $\begin{array}{c}0.0005 \\
(0.53) \\
\mathbf{0 . 0 0 0 1}\end{array}$ & & $\begin{array}{c}-0.002 \\
(-1.67) \\
-\mathbf{0 . 0 0 0 3}\end{array}$ \\
\hline Number of outlets & & $\begin{array}{c}0.262 \\
(1.75) \\
\mathbf{0 . 0 6 1}\end{array}$ & & $\begin{array}{c}-0.057 \\
(-0.59) \\
-\mathbf{0 . 0 0 9}\end{array}$ \\
\hline Percent dry & & $\begin{array}{c}-0.021 \\
(-1.86) \\
-\mathbf{0 . 0 0 5}\end{array}$ & & $\begin{array}{c}0.001 \\
(0.18) \\
\mathbf{0 . 0 0 0 2}\end{array}$ \\
\hline Grocery sales of beer prohibited & & $\begin{array}{r}0.117 \\
(0.30) \\
\mathbf{0 . 0 2 9}\end{array}$ & & $\begin{array}{r}0.357 \\
(1.38) \\
\mathbf{0 . 0 7 0}\end{array}$ \\
\hline Billboards prohibited & & $\begin{array}{r}0.168 \\
(0.47) \\
\boldsymbol{0 . 0 4 2}\end{array}$ & & $\begin{array}{c}-0.081 \\
(-0.37) \\
-\mathbf{0 . 0 1 3}\end{array}$ \\
\hline Window displays prohibited & & $\begin{array}{c}-0.478 \\
(-1.76) \\
-\mathbf{0 . 0 9 8}\end{array}$ & & $\begin{array}{c}-0.015 \\
(-0.11) \\
-\mathbf{0 . 0 0 2}\end{array}$ \\
\hline Consumer novelties prohibited & & $\begin{array}{c}0.327 \\
(1.10) \\
\mathbf{0 . 0 8 5}\end{array}$ & & $\begin{array}{r}0.135 \\
(0.43) \\
\mathbf{0 . 0 2 3}\end{array}$ \\
\hline Price advertising prohibited & & $\begin{array}{c}0.115 \\
(0.73) \\
\boldsymbol{0 . 0 2 7}\end{array}$ & & $\begin{array}{c}-0.065 \\
(-0.33) \\
-\mathbf{0 . 0 1 0}\end{array}$ \\
\hline $\mathrm{N}$ & 623 & 623 & 1,638 & 1,638 \\
\hline Log likelihood & -254.678 & -249.102 & -516.697 & -511.923 \\
\hline $\begin{array}{l}\text { Chi-squared on availability } \\
\text { variables }\end{array}$ & & $\begin{array}{l}7.89 \\
{[0.048]}\end{array}$ & & $\begin{array}{c}2.42 \\
{[0.490]}\end{array}$ \\
\hline $\begin{array}{l}\text { Chi-squared on advertising } \\
\text { variables }\end{array}$ & & $\begin{array}{c}3.36 \\
{[0.500]}\end{array}$ & & $\begin{array}{c}0.33 \\
{[0.988]}\end{array}$ \\
\hline
\end{tabular}

Note: T-statistics in parenthesis, marginal effects in bold italics, $p$-values in brackets for chi-squared tests, and intercept not shown. Other regressors include family history of violence, the respondent's age, income, race, employment status, religion and measures of stress, single parent status (1985 only) and the child's age and sex. 
Table 2

Probit Estimates of Severe Violence by Males

1976

1985

(1)

(2)

(3)

(4)

\begin{tabular}{lc}
\hline State excise tax on beer & -0.190 \\
$(-1.29)$ \\
$\mathbf{- 0 . 0 2 3}$
\end{tabular}

Marijuana decriminalization

$-0.023$

$-0.004$

$(-0.02)$

$-0.0005$

0.228

$(2.04)$

0.017

0.296

(2.17)

$-0.232$

$(-0.28)$

$-0.021$

0.019

0.110

$(0.78)$

0.007

Cocaine price

$-0.002$

$(-1.51)$

$-0.001$

$-0.0002$

$(-0.55)$

0.261

$-0.0001$

Number of outlets

$(1.50)$

0.138

0.029

(1.06)

0.009

Percent dry

0.010

0.012

(0.66)

(1.62)

0.001

0.001

Grocery sales of beer prohibited

$-0.171$

$-0.067$

$(-0.25)$

$(-0.17)$

$-0.017$

$-0.004$

Billboards prohibited

0.059

(0.13)

0.007

$-0.464$

$(-1.38)$

$-0.023$

Window displays prohibited

0.268

$(0.80)$

$-0.075$

0.033

$(-0.39)$

$-0.005$

Consumer novelties prohibited

$-0.331$

$(-0.78)$

0.830

(2.09)

$-0.031$

0.106

Price advertising prohibited

$-0.145$

$-0.022$

$(-0.68)$

$(-0.08)$

$-0.015$

$-0.001$

$\mathrm{N}$

499

499

1,037

1,037

Log likelihood

$-137.576$

$-134.551$

$-301.479$

$-297.365$

2.43

[0.488]

2.97

[0.396] variables

1.49

4.73

[0.829]

[0.317]

Note: T-statistics in parenthesis, marginal effects in bold italics, p-values in brackets for chi-squared tests, and intercept not shown. Other regressors include family history of violence, the respondent's age, income, race, employment status, religion and measures of stress, single parent status (1985 only) and the child's age and sex. 
Table 3

Pooled Years

Probit Estimates of Severe Violence

FEMALES

MALES

Without

With

Without

With

State Dummies State Dummies

State Dummies State Dummies

$(\mathrm{N}=2,261)$

$(\mathrm{N}=2,231)$

$(\mathrm{N}=1,561)$

$(\mathrm{N}=1,479)$

\begin{tabular}{|c|c|c|c|c|c|c|c|c|}
\hline & $(1)$ & (2) & (3) & (4) & $(5)$ & (6) & (7) & $(8)$ \\
\hline State excise tax on beer & $\begin{array}{c}-0.247 \\
(-3.71) \\
-\mathbf{0 . 0 4 7}\end{array}$ & $\begin{array}{c}-0.202 \\
(-2.71) \\
-\mathbf{0 . 0 3 8}\end{array}$ & $\begin{array}{c}-0.256 \\
(-1.22) \\
-0.047\end{array}$ & $\begin{array}{c}-0.257 \\
(-1.09) \\
\mathbf{- 0 . 0 4 7}\end{array}$ & $\begin{array}{c}-0.013 \\
(-0.17) \\
-0.002\end{array}$ & $\begin{array}{c}0.032 \\
(0.34) \\
0.005\end{array}$ & $\begin{array}{c}-0.944 \\
(-2.84) \\
-\mathbf{0 . 1 3 6}\end{array}$ & $\begin{array}{c}-0.632 \\
(-1.78) \\
-\mathbf{- 0 . 0 8 9}\end{array}$ \\
\hline Marijuana decriminalization & & $\begin{array}{c}0.014 \\
(0.14) \\
0.003\end{array}$ & & $\begin{array}{c}-0.040 \\
(-0.21) \\
\mathbf{- 0 . 0 0 7}\end{array}$ & & $\begin{array}{r}0.011 \\
(0.09) \\
\mathbf{0 . 0 0 2}\end{array}$ & & $\begin{array}{c}-0.013 \\
(-0.05) \\
-\mathbf{- 0 . 0 0 2}\end{array}$ \\
\hline Cocaine price & & $\begin{array}{l}-0.001 \\
(-1.31) \\
-\mathbf{0 . 0 0 0 1}\end{array}$ & & $\begin{array}{c}0.001 \\
(0.63) \\
\mathbf{0 . 0 0 0 2}\end{array}$ & & $\begin{array}{l}-0.001 \\
(-1.61) \\
-\mathbf{0 . 0 0 0 2}\end{array}$ & & $\begin{array}{c}0.001 \\
(0.41) \\
\boldsymbol{0 . 0 0 0 1}\end{array}$ \\
\hline Number of outlets & & $\begin{array}{c}-0.010 \\
(-0.13) \\
-\mathbf{0 . 0 0 2}\end{array}$ & & $\begin{array}{c}0.665 \\
(1.18) \\
\mathbf{0 . 1 2 2}\end{array}$ & & $\begin{array}{c}0.063 \\
(0.70) \\
\mathbf{0 . 0 1 0}\end{array}$ & & $\begin{array}{c}-0.407 \\
(-0.49) \\
-\mathbf{- 0 . 0 5 7}\end{array}$ \\
\hline Percent dry & & $\begin{array}{c}-0.003 \\
(-0.70) \\
-\mathbf{0 . 0 0 1}\end{array}$ & & $\begin{array}{c}0.028 \\
(0.88) \\
\mathbf{0 . 0 0 5}\end{array}$ & & $\begin{array}{r}0.006 \\
(1.09) \\
0.001\end{array}$ & & $\begin{array}{c}-0.090 \\
(-1.70) \\
-\mathbf{- 0 . 0 1 3}\end{array}$ \\
\hline Grocery sales of beer prohibited & & $\begin{array}{c}0.376 \\
(2.05) \\
\mathbf{0 . 0 8 6}\end{array}$ & & & & $\begin{array}{c}-0.066 \\
(-0.24) \\
-\mathbf{0 . 0 1 0}\end{array}$ & & \\
\hline Billboards prohibited & & $\begin{array}{c}-0.044 \\
(-0.28) \\
-\mathbf{0 . 0 0 8}\end{array}$ & & $\begin{array}{c}-0.512 \\
(-1.59) \\
\mathbf{- 0 . 0 7 5}\end{array}$ & & $\begin{array}{c}0.073 \\
(0.36) \\
\mathbf{0 . 0 1 2}\end{array}$ & & $\begin{array}{c}-0.406 \\
(-0.81) \\
-\mathbf{0 . 0 4 6}\end{array}$ \\
\hline Window displays prohibited & & $\begin{array}{c}-0.025 \\
(-0.24) \\
-\mathbf{0 . 0 0 5}\end{array}$ & & $\begin{array}{c}0.588 \\
(1.77) \\
\mathbf{0 . 1 2 9}\end{array}$ & & $\begin{array}{c}-0.016 \\
(-0.12) \\
-0.002\end{array}$ & & $\begin{array}{r}0.012 \\
(0.03) \\
0.002\end{array}$ \\
\hline Consumer novelties prohibited & & $\begin{array}{c}-0.087 \\
(-0.53) \\
-\mathbf{0 . 0 1 6}\end{array}$ & & $\begin{array}{c}-0.323 \\
(-1.13) \\
\mathbf{- 0 . 0 5 0}\end{array}$ & & $\begin{array}{c}-0.101 \\
(-0.50) \\
-\mathbf{0 . 0 1 5}\end{array}$ & & $\begin{array}{c}-0.249 \\
(-0.74) \\
-\mathbf{- 0 . 0 3 0}\end{array}$ \\
\hline Price advertising prohibited & & $\begin{array}{c}0.004 \\
(0.03) \\
\boldsymbol{0 . 0 0 1}\end{array}$ & & $\begin{array}{c}0.072 \\
(0.37) \\
\mathbf{0 . 0 1 4}\end{array}$ & & $\begin{array}{c}-0.103 \\
(-0.70) \\
-\mathbf{0 . 0 1 5}\end{array}$ & & $\begin{array}{r}-0.443 \\
(-1.77) \\
-\mathbf{- 0 . 0 5 2}\end{array}$ \\
\hline 1976 & $\begin{array}{c}0.371 \\
(4.02) \\
\mathbf{0 . 0 7 8}\end{array}$ & $\begin{array}{c}0.695 \\
(2.65) \\
\mathbf{0 . 1 5 7}\end{array}$ & $\begin{array}{c}0.349 \\
(3.05) \\
\boldsymbol{0 . 0 7 1}\end{array}$ & $\begin{array}{c}-0.006 \\
(-0.01) \\
-\mathbf{0 . 0 0 1}\end{array}$ & $\begin{array}{c}0.094 \\
(0.84) \\
\mathbf{0 . 0 1 5}\end{array}$ & $\begin{array}{c}0.656 \\
(1.85) \\
\mathbf{0 . 1 1 7}\end{array}$ & $\begin{array}{c}0.453 \\
(2.89) \\
\boldsymbol{0 . 0 7 3}\end{array}$ & $\begin{array}{c}0.205 \\
(0.22) \\
\mathbf{0 . 0 3 0}\end{array}$ \\
\hline Log likelihood & -806.828 & -801.445 & -785.069 & -781.912 & -467.958 & -465.048 & -434.376 & -428.822 \\
\hline Likelihood ratio test for pooling & 70.90 & 80.84 & & & 57.81 & 66.26 & & \\
\hline $\begin{array}{l}\text { Chi-squared on state dummy } \\
\text { variables }\end{array}$ & & & $\begin{array}{l}32.05 \\
{[0.867]}\end{array}$ & $\begin{array}{l}31.41 \\
{[0.884]}\end{array}$ & & & $\begin{array}{l}37.96 \\
{[0.426]}\end{array}$ & $\begin{array}{l}41.61 \\
{[0.242]}\end{array}$ \\
\hline $\begin{array}{l}\text { Chi-squared on availability } \\
\text { variables }\end{array}$ & & $\begin{array}{l}4.43 \\
{[0.218]}\end{array}$ & & $\begin{array}{l}1.62 \\
{[0.446]}\end{array}$ & & $\begin{array}{l}1.33 \\
{[0.722]}\end{array}$ & & $\begin{array}{c}2.90 \\
{[0.235]}\end{array}$ \\
\hline $\begin{array}{l}\text { Chi-squared on advertising } \\
\text { variables }\end{array}$ & & $\begin{array}{l}0.61 \\
{[0.961]}\end{array}$ & & $\begin{array}{l}4.74 \\
{[0.315]}\end{array}$ & & $\begin{array}{l}0.95 \\
{[0.918]}\end{array}$ & & $\begin{array}{c}6.91 \\
{[0.141]}\end{array}$ \\
\hline
\end{tabular}

Note: T-statistics in parenthesis, marginal effects in bold italics, p-values in brackets for chi-squared tests, and intercept not shown. Other regressors include family history of violence, the respondent's age, income, race, employment status, religion and measures of stress, single parent status, and the child's age and sex. 
Table 4

Structural Equations

FEMALES

MALES

\begin{tabular}{|c|c|c|c|c|}
\hline & $\begin{array}{l}\text { OLS } \\
(1)\end{array}$ & $\begin{array}{c}\text { TSLS } \\
(2)\end{array}$ & $\begin{array}{l}\text { OLS } \\
(3)\end{array}$ & $\begin{array}{c}\text { TSLS } \\
(4)\end{array}$ \\
\hline & & $\begin{array}{l}\text { Beer tax is } \\
\text { only } \\
\text { instrument }\end{array}$ & & $\begin{array}{l}\text { Beer tax is } \\
\text { only } \\
\text { instrumen }\end{array}$ \\
\hline \multicolumn{5}{|l|}{1976} \\
\hline Dichotomous indicator of drunkenness & $\begin{array}{c}0.072 \\
(0.89)\end{array}$ & $\begin{array}{c}4.546 \\
(1.67)\end{array}$ & $\begin{array}{c}0.029 \\
(0.64)\end{array}$ & $\begin{array}{c}0.830 \\
(0.96)\end{array}$ \\
\hline Hausman chi-squared test for exogenity & & 2.72 & & 0.85 \\
\hline First stage estimates of beer tax & & $\begin{array}{l}-0.014 \\
(-1.68)\end{array}$ & & $\begin{array}{r}-0.027 \\
(-1.33)\end{array}$ \\
\hline $\mathrm{N}$ & & 608 & & 516 \\
\hline \multicolumn{5}{|l|}{1985} \\
\hline Dichotomous indicator of drunkenness & $\begin{array}{r}0.053 \\
(1.27)\end{array}$ & $\begin{array}{r}1.582 \\
(1.54)\end{array}$ & $\begin{array}{r}0.036 \\
(1.21)\end{array}$ & $\begin{array}{l}-1.288 \\
(-1.15)\end{array}$ \\
\hline Hausman chi-squared test for exogenity & & 2.21 & & 1.41 \\
\hline First stage estimates of beer tax & & $\begin{array}{r}-0.019 \\
(-2.00)\end{array}$ & & $\begin{array}{l}-0.032 \\
(-1.56)\end{array}$ \\
\hline $\mathrm{N}$ & & 1,636 & & 1,033 \\
\hline $\begin{array}{l}\text { POOLED } \\
\text { Dichotomous indicator of drunkenness }\end{array}$ & $\begin{array}{c}0.057 \\
(1.55)\end{array}$ & $\begin{array}{r}2.077 \\
(2.65)\end{array}$ & $\begin{array}{c}0.040 \\
(1.61)\end{array}$ & $\begin{array}{c}0.075 \\
(0.22)\end{array}$ \\
\hline Hausman chi-squared test for exogenity & & 6.63 & & 0.01 \\
\hline First stage estimates of beer tax & & $\begin{array}{l}-0.020 \\
(-3.12)\end{array}$ & & $\begin{array}{l}-0.036 \\
(-2.58)\end{array}$ \\
\hline $\mathrm{N}$ & & 2,244 & & 1,549 \\
\hline
\end{tabular}

Note: T-statistics in parenthesis, and intercept not shown. Critical values for Hausman test are 3.84 at 5 percent and 6.63 at 1 percent. Critical values for tests of all the regulatory variables as instruments (column 3 ) are 18.31 at 5 percent and 23.21 at one percent. Other regressions include family history of violence, the respondent's age, income, race, employment status, religion and measures of stress, and the child's age and sex. 
Table 5

Individual Characteristics

\begin{tabular}{|c|c|c|c|c|}
\hline & $\begin{array}{c}\text { Females } \\
1976\end{array}$ & $\begin{array}{c}\text { Females } \\
1985\end{array}$ & $\begin{array}{c}\text { Males } \\
1976\end{array}$ & $\begin{array}{c}\text { Males } \\
1985\end{array}$ \\
\hline \multirow{3}{*}{ State excise tax on beer } & -0.347 & -0.211 & -0.190 & 0.228 \\
\hline & $(-3.36)$ & $(-2.19)$ & $(-1.29)$ & $(2.04)$ \\
\hline & -0.082 & -0.034 & -0.023 & 0.017 \\
\hline \multirow{3}{*}{ Parents hit respondent } & 0.248 & 0.299 & 0.271 & 0.313 \\
\hline & (1.59) & $(3.17)$ & (1.19) & $(2.51)$ \\
\hline & 0.057 & 0.049 & 0.029 & 0.022 \\
\hline \multirow[t]{3}{*}{ Parents hit each other } & -0.048 & 0.433 & 0.070 & 0.149 \\
\hline & $(-0.26)$ & $(4.20)$ & $(0.29)$ & $(1.02)$ \\
\hline & -0.011 & 0.084 & 0.009 & 0.012 \\
\hline \multirow{3}{*}{ Black } & 0.269 & 0.557 & 0.136 & 0.193 \\
\hline & $(0.98)$ & $(4.00)$ & $(0.39)$ & $(0.86)$ \\
\hline & 0.071 & 0.119 & 0.018 & 0.016 \\
\hline \multirow[t]{3}{*}{ Hispanic } & 0.636 & 0.206 & -0.671 & -0.620 \\
\hline & (2.07) & (1.16) & $(-1.38)$ & $(-1.72)$ \\
\hline & 0.193 & 0.038 & -0.049 & -0.027 \\
\hline \multirow[t]{3}{*}{ Other race } & -0.145 & -0.053 & & -0.146 \\
\hline & $(-0.23)$ & $(-0.27)$ & -- & $(-0.64)$ \\
\hline & -0.032 & -0.008 & & -0.010 \\
\hline \multirow{3}{*}{ Education } & -0.0004 & 0.020 & 0.059 & -0.026 \\
\hline & $(-0.01)$ & $(0.99)$ & (1.38) & $(-1.12)$ \\
\hline & -0.0001 & 0.003 & 0.007 & -0.002 \\
\hline \multirow[t]{3}{*}{ Age } & -0.040 & -0.005 & -0.006 & 0.011 \\
\hline & $(-3.44)$ & $(-0.64)$ & $(-0.49)$ & $(1.42)$ \\
\hline & -0.009 & -0.001 & -0.001 & 0.001 \\
\hline \multirow[t]{3}{*}{ Income } & -0.005 & -0.005 & -0.001 & -0.007 \\
\hline & $(-1.06)$ & $(-1.18)$ & $(-0.17)$ & $(-1.34)$ \\
\hline & -0.001 & -0.001 & -0.0001 & -0.0005 \\
\hline \multirow[t]{3}{*}{ Female child } & -0.126 & -0.092 & -0.565 & -0.349 \\
\hline & $(-0.96)$ & $(-1.05)$ & $(-3.04)$ & $(-2.98)$ \\
\hline & -0.030 & -0.015 & -0.067 & -0.026 \\
\hline \multirow{3}{*}{ Age of child } & -0.007 & -0.003 & -0.120 & -0.021 \\
\hline & $(-0.36)$ & $(-0.24)$ & $(-4.36)$ & $(-1.59)$ \\
\hline & -0.002 & -0.0004 & -0.014 & -0.002 \\
\hline \multirow{3}{*}{ Number children at home } & 0.088 & 0.146 & 0.169 & 0.085 \\
\hline & $(1.72)$ & $(3.38)$ & $(2.11)$ & $(1.54)$ \\
\hline & 0.021 & 0.024 & 0.020 & 0.006 \\
\hline \multirow[t]{3}{*}{ Part-time } & -0.170 & 0.078 & & -0.137 \\
\hline & $(-0.81)$ & $(0.59)$ & -- & $(-0.38)$ \\
\hline & -0.038 & 0.013 & & -0.009 \\
\hline \multirow[t]{3}{*}{ Unemployed } & -0.170 & 0.072 & 0.008 & -0.565 \\
\hline & $(-0.34)$ & $(0.49)$ & $(0.02)$ & $(-1.59)$ \\
\hline & -0.037 & 0.012 & 0.001 & -0.026 \\
\hline \multirow[t]{3}{*}{ Not employed } & -0.222 & 0.089 & 0.745 & -0.273 \\
\hline & $(-1.27)$ & $(0.81)$ & (1.93) & $(-0.98)$ \\
\hline & -0.054 & 0.015 & 0.143 & -0.016 \\
\hline \multirow[t]{3}{*}{ Blue collar } & 0.091 & 0.081 & 0.379 & -0.083 \\
\hline & $(0.59)$ & $(0.85)$ & (1.65) & $(-0.68)$ \\
\hline & 0.022 & 0.013 & 0.044 & -0.006 \\
\hline \multirow[t]{3}{*}{ Catholic } & -0.616 & 0.751 & 0.443 & 0.198 \\
\hline & $(-2.54)$ & $(1.55)$ & $(1.26)$ & $(0.56)$ \\
\hline & -0.127 & 0.151 & 0.064 & 0.016 \\
\hline \multirow[t]{3}{*}{ Jewish } & & 0.722 & 0.221 & -41.939 \\
\hline & -- & (1.13) & $(0.45)$ & $(-0.95)$ \\
\hline & & 0.177 & 0.030 & -0.082 \\
\hline
\end{tabular}


Table 5 (continued)

$\begin{array}{lcccc}\text { Protestant } & -0.301 & 0.631 & 0.175 & 0.046 \\ & (-1.36) & (1.31) & (0.53) & (0.13) \\ \text { No religion } & -\mathbf{0 . 0 7 3} & \mathbf{0 . 0 9 3} & \mathbf{0 . 0 2 0} & \mathbf{0 . 0 0 3} \\ & -0.496 & 0.944 & -0.603 & 0.277 \\ \text { Frequency of religious services } & (-1.25) & (1.88) & (-1.22) & (0.72) \\ & \mathbf{- 0 . 0 9 1} & \mathbf{0 . 2 4 3} & \mathbf{- 0 . 0 4 8} & \mathbf{0 . 0 2 5} \\ & -0.010 & & -0.046 & \\ \text { Talks with others } & (-0.33) & -- & (-1.18) & -- \\ & -\mathbf{0 . 0 0 2} & & \mathbf{- 0 . 0 0 5} & \\ \text { Stress } & 0.223 & 0.264 & 0.016 & 0.177 \\ & (1.55) & (2.69) & (0.08) & (1.06) \\ \text { Single parent } & \mathbf{0 . 0 5 2} & \mathbf{0 . 0 4 6} & \mathbf{0 . 0 0 2} & \mathbf{0 . 0 1 5} \\ & -0.029 & 0.151 & 0.037 & 0.037 \\ & (-0.83) & (3.52) & (0.94) & (0.70) \\ & -\mathbf{0 . 0 0 7} & \mathbf{0 . 0 2 4} & \mathbf{0 . 0 0 4} & \mathbf{0 . 0 0 3} \\ & & -0.125 & & 0.256 \\ & -- & (-1.05) & -- & (1.01) \\ & & -\mathbf{0 . 0 1 9} & & \mathbf{0 . 0 2 3}\end{array}$

